\title{
Uev1A facilitates osteosarcoma differentiation by promoting Smurf1-mediated Smad1 ubiquitination and degradation
}

\author{
Weiwei Zhang ${ }^{1,3}$, Yuan Zhuang ${ }^{1,3}$, Yiran Zhang ${ }^{1}$, Xiaoran Yang ${ }^{1}$, Hong Zhang ${ }^{1}$, Guifen Wang ${ }^{1}$, Wanqi Yin ${ }^{1}$, Ruifeng Wang ${ }^{1}$, \\ Zhiling Zhang ${ }^{1}$ and Wei Xiao*,1,2
}

\begin{abstract}
Malignant bone tumor osteosarcoma (OS) displays high metastasis incidence and poor prognosis. Its stem cell properties could serve to explain tumor recurrence and resistance to conventional treatments. In this study, we identified UEV1A as a novel suppressor of OS. Elevated UEV1A diminishes stem cell properties of OS cells and drives them to terminal differentiation. Importantly, UEV1A-overexpressed OS cells delay proliferation and are more sensitive to chemotherapeutic agents than control cells. Uev1A appears to be involved in the BMP signaling pathway in which it collaborates with a ubiquitin E3 ligase Smurf1 to promote Smad1 degradation in a Ubc13-independent manner. Indeed, Smad1 is identified as a dominant downstream effector of Uev1A, which unravels the mechanism underlying Uev1A-orchestrated tumor suppression in OS. The above findings identify UEV1A as a potential OS tumor suppression gene, and shed lights to future OS diagnosis and treatment.
\end{abstract}

Cell Death and Disease (2017) 8, e2974; doi:10.1038/cddis.2017.366; published online 3 August 2017

Osteosarcoma (OS) is a malignant bone tumor that displays high metastasis incidence and chemoresistance. ${ }^{1,2}$ Conventional treatments of OS usually combine surgical resection with radiotherapy or chemotherapy, such as isofosfamide, doxorubicin, cisplatin and methotrexate. However, the prognosis of OS patients is poor, especially for those who present metastasis. ${ }^{3-5}$ Thus, it is necessary to identify a more efficient therapy to cure OS. Recent studies suggest that OS derives from defect in differentiation of mesenchymal stem cells (MSCs). ${ }^{6,7}$ MSC differentiation can be divided into several stages including MSCs, committed osteoprogenitor, proosteoblast, early osteoblast, mature osteoblast and osteocyte $^{8}$ which can be characterized by their representative marker gene expression. For example, inhibitors of differentiation (IDs) have the highest expression level in MSCs and support high proliferating capability of cells. ${ }^{9,10}$ During differentiation, the expression of $I D$ genes markedly decreases, whereas those of RUNX2 and OSTERIX increase. ${ }^{11}$ Runx2 and Osterix are important osteogenic regulators exhibiting the highest level in the pro-osteoblast stage. ${ }^{8}$ Late markers like osteocalcin (OC) and osteopontin (OPN, SPP1) feature mature osteoblasts and osteocytes. ${ }^{8}$ As block of differentiation leads to gathering of stem cell-like cells that maintain high proliferation capability, it is assumed that defect in any of these MSC differentiation stages may result in OS. These properties of OS cells appear to be similar to those of cancer stem cells (CSCs) with elevated expression of stem cell marker genes. ${ }^{12,13}$ Although accounting for a small cancer cell population, CSCs seem to orchestrate cancer recurrence and resistance to conventional treatments. ${ }^{14,15}$ Reduction of CSCs by inducing differentiation or disrupting CSC niche may sensitize cancer cells to chemotherapy or radiotherapy.

Ubiquitin-conjugating enzyme (Ubc) E2 variants (Uevs) are related to Ubc in sequence but do not contain the active Cys residue for ubiquitination. ${ }^{16,17}$ Uevs specifically interact with Ubc13, which is the only E2 dedicated to mediate K63-linked poly-Ub chain assembly. ${ }^{18,19}$ Several lines of evidence support a close correlation between UEV1A and carcinogenesis, probably because it forms a stable complex with Ubc13 to activate the NF-kB pathway, ${ }^{20,21}$ which promotes tumorigenesis and metastasis. ${ }^{22}$ Uev1A is negatively correlated with differentiation as its expression is diminished upon differentiation in human colon adenocarcinoma cells. ${ }^{17}$ Interestingly, previous studies show that the NF- $\kappa \mathrm{B}$ signaling is involved in controlling osteolineage specification. ${ }^{23-25}$ Therefore, as a key activator of this pathway, Uev1A could have a potential role in regulating poorly differentiated OS. In this study, we identified Uev1A as a novel OS regulator and found that it works with a E2-E3 complex UbcH5B-Smurf1 to facilitate the ubiquitination and degradation of an OS promoting factor Smad1, which reveals a critical role of Uev1A in promoting osteoblast differentiation and preventing OS. Importantly, UEV1A-driven OS differentiation markedly inhibits the 'stemness' of OS cells, which confers OS cell sensitivity to chemotherapeutic agents. Hence, enhanced Uev1A activity may serve as a means of treating OS.

\footnotetext{
${ }^{1}$ College of Life Sciences, Capital Normal University, Beijing, China and ${ }^{2}$ Department of Microbiology and Immunology, University of Saskatchewan, Saskatoon, Saskatchewan, Canada

*Corresponding author: W Xiao, Department of Microbiology and Immunology, University of Saskatchewan, 107 Wiggins Road, Saskatoon, SK S7N 5E5, Canada. Tel: +1 306966 4308; Fax: +1 306966 4311; E-mail: wei.xiao@usask.ca

${ }^{3}$ These authors contributed equally to this work.

Received 26.1.17; revised 06.6.17; accepted 02.7.17; Edited by M Daugaard
} 


\section{Results}

Uev1A promotes differentiation of OS cells in a Ubc13independent manner. To investigate the role of Uev1A in regulating $\mathrm{OC}$ cell differentiation, first of all, we screened its expression in multiple OC cell lines, including FOB, 143B, U2OS and Saos2 cells. Compared with the normal FOB osteoblast cells, only U2OS cells displayed a significantly reduced expression of Uev1A (Figure 1a). Next, we induced U2OS cells to differentiate through culturing them in osteogenic medium for 4 weeks. A Red S staining assay was used to detect mineralization in osteoblast cells. As expected, an obviously enhanced mineralization signal was detected in the osteogenic medium-cultured cells (Figure 1b), and the $O C$ mRNA level was elevated by fourfold (Figure 1c) along with corresponding increase in the OC protein level (Figure 1d), indicating a successful induction of terminal differentiation. Interestingly, although the expression of UEV1A did not exhibit obvious change in the early differentiation stage, a fivefold induction of its mRNA was observed in the fully differentiated cells (Supplementary Figure S1; Figure 1e), suggesting that UEV1A expression is positively correlated to OC cell differentiation.

The elevated expression appears to be specific for UEV1A, as the expression of its splicing variant UEV1C or a homologous gene MMS2 was not markedly altered (Figure 1e). We reasoned that if UEV1A has a critical role in the OS differentiation, its depletion should reverse the differentiation process of OS cells. Indeed, expression of two independent UEV1 short-hairpin RNAs (shRNAs) diminished the osteogenic medium-induced UEV1A and reverted the elevated $O C$ expression, whereas the SPP1 expression was reduced
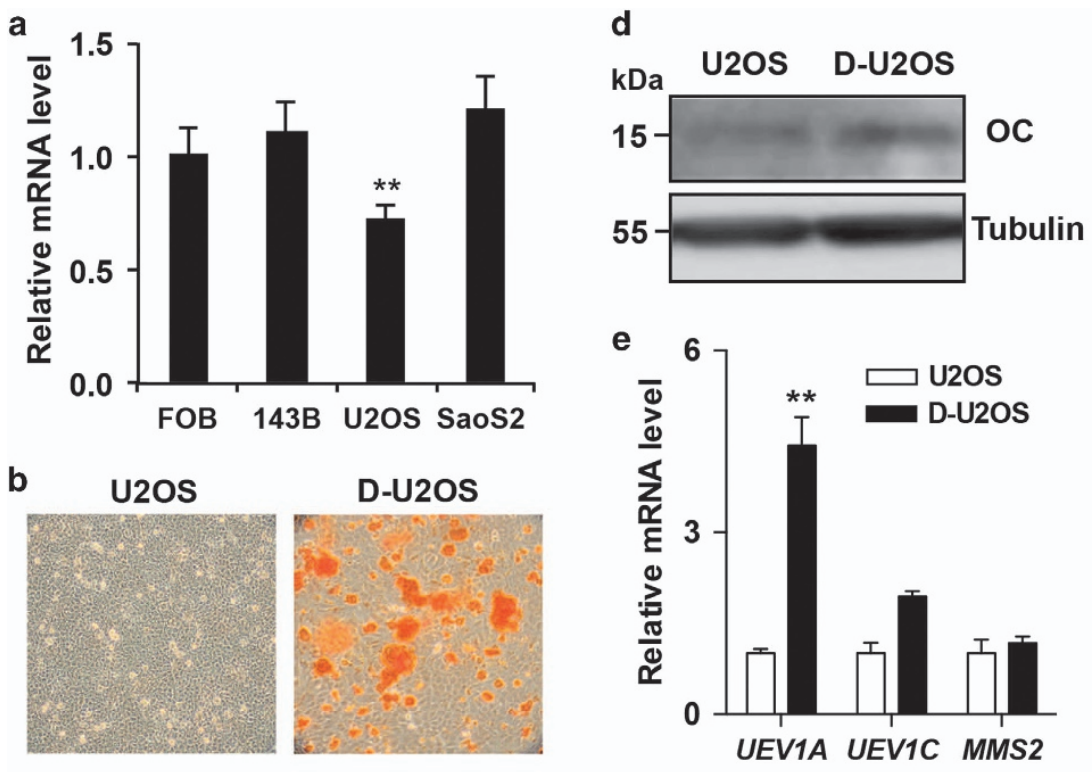

D-U2OS
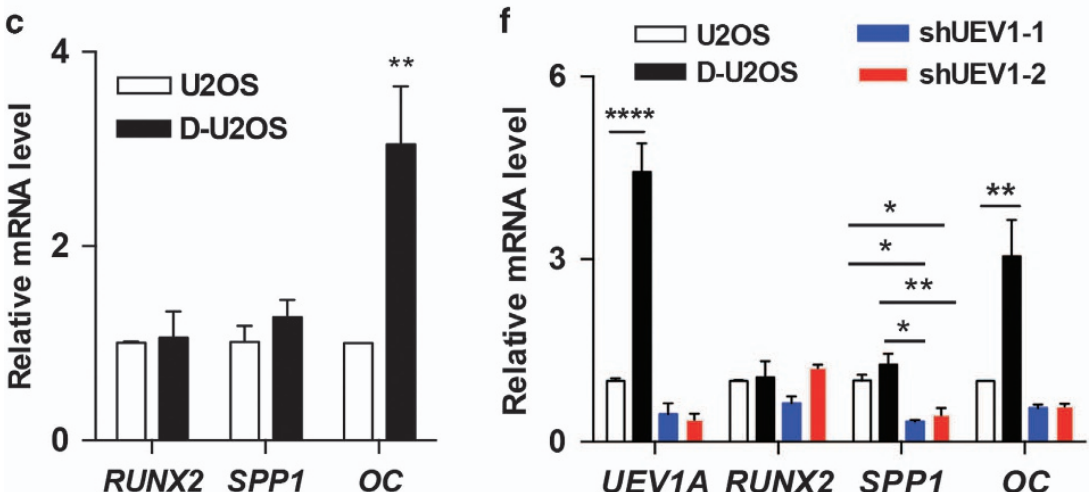

Figure 1 Uev1A fluctuation during OS cell differentiation. (a) The expression of Uev1A in multiple OC cell lines. (b) Establishment of differentiated OS cells. U2OS cells were induced to differentiate through culturing them in an osteogenic medium for 4 weeks followed by Red S staining. (c) Altered expression of differentiation marker genes upon cell differentiation. The gene expression was measured by qRT-PCR. Data are presented as the mean \pm S.D. (d) Alteration of OC protein levels during differentiation. Cell lysates were analyzed by western blot using anti-OC and anti-tubulin antibodies. (e) Alteration of UEV1A and other UEV transcript levels upon cell differentiation. The transcripts of UEV1A, UEV1C and MMS2 were analyzed by qRT-PCR. Data are presented as the mean \pm S.D. (f) Reversal of OS differentiation by UEV1 depletion. ShRNA-mediated UEV1 knockdown was performed in the differentiated U2OS cells. Two different anti-UEV1 shRNA sequences were used to reduce off-target effects. Four days after transfection, total RNA was extracted for the qRT-PCR assay. The expression levels of Uev1A and marker genes in D-U2OS and shRNA-transfected D-U2OS cells are normalized to their corresponding values in empty vector-transfected wild-type U2OS cells. Data are the mean \pm S.D. D-U2OS: differentiated U2OS cells 

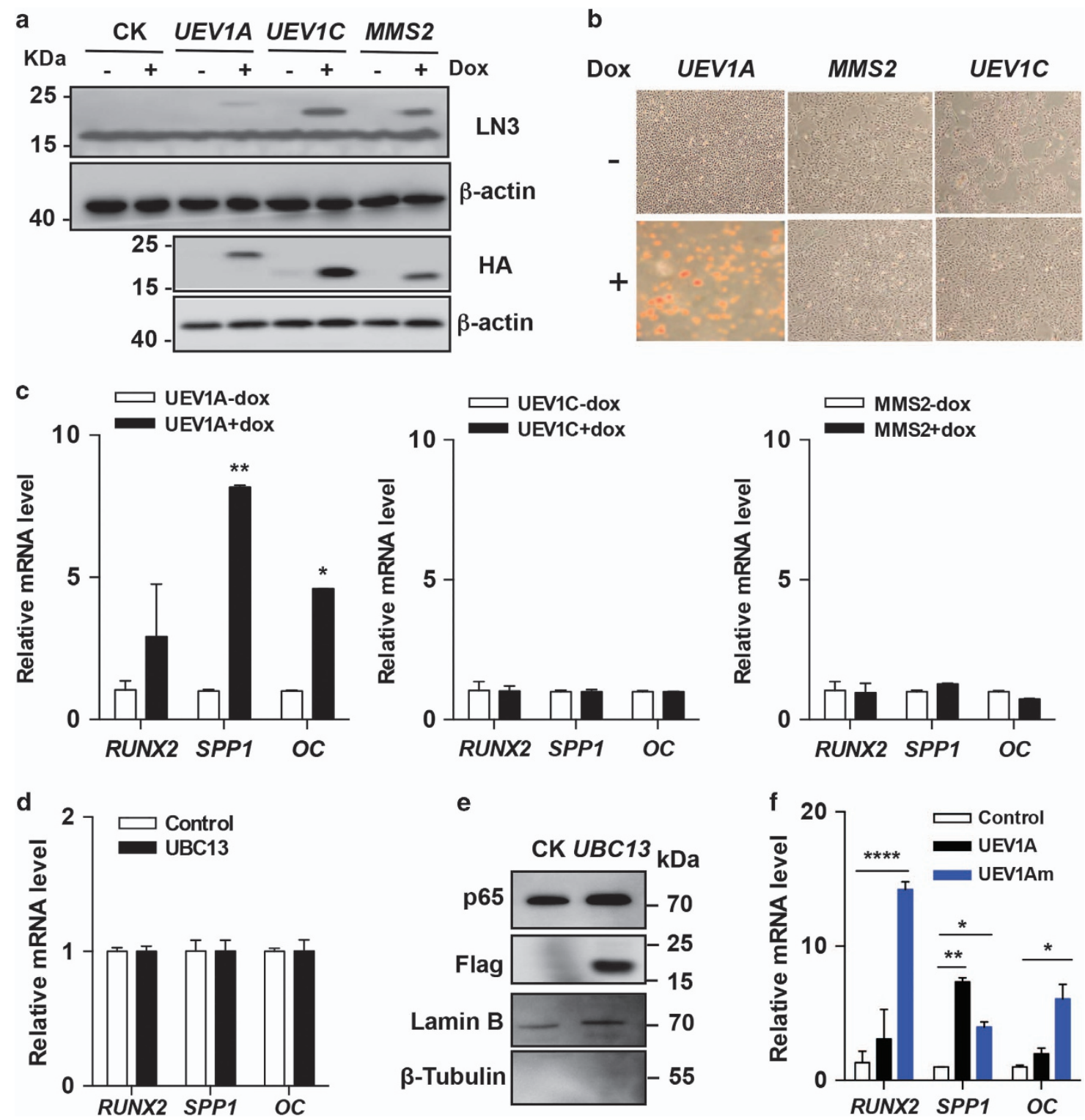

Figure 2 Uev1A promotes U2OS cell differentiation independently of Ubc13. (a) Establishment of Dox-inducible UEV1 and MMS2 overexpression U2OS stable cell lines. Each gene was fused with a 3xHA tag at the $\mathrm{N}$-terminus before cloning into the mammalian expression vector pcDNA4/TO. Cell lysates were analyzed by western blot (WB) using anti-Uev1/Mms2 (LN3), anti-HA and anti-actin antibodies. (b) UEV1A overexpression drives U2OS cells to terminal differentiation as indicated by Red S staining. (c-e) U2OS cells were transiently transfected with constructs expressing the genes as indicated. Four days after transfection, total RNAs were harvested for the qRT-PCR and WB analyses. Data are presented as the mean \pm S.D. (c) The transcript levels of differentiation markers in UEV1A-, UEV1C- and MMS2-overexpressed stable cell lines as measured by qRT-PCR. (d) Overexpression of UBC13 does not alter the OS differentiation marker gene expression. (e) Western blotting showing p65 nuclear translocation upon UBC13 overexpression. (f) A Uev1A mutant (Uev1Am) incapable of interacting with Ubc13 causes stronger differentiation marker gene expression than wild-type Uev1A

by threefold (Figure 1f). As $O C$ and SPP1 are the marker genes of osteocytes, ${ }^{8}$ the inhibition of their expression indicates a failure in U2OS terminal differentiation.

To further explore the role of UEV1A in OS differentiation, we established Dox-inducible stable U2OS cell lines that expressed ectopic UEV1A fused with an HA tag (Figure 2a). In parallel, stable cell lines expressing UEV1C or MMS2 were also generated to serve as controls. Owing to the high degree of similarity in sequence among Uev1A, Uev1C and Mms2, our homemade monoclonal antibody LN3 raised against
Uev1A could also detect Uev1C and Mms2 (Figure 2a). Upon Dox-induced UEV1A overexpression, mineralization signals were detected in UEV1A-overexpressed U2OS cells but not in UEV1C or MMS2-overexpressed cells (Figure 2b). Meanwhile, the expression levels of late marker genes $O C$ and SPP1 were markedly elevated, along with a moderate increase in RUNX2 expression (Figure 2c, left panel), indicating that majority of them were terminally differentiated. In sharp contrast, neither UEV1C nor MMS2 overexpression altered the above differentiation marker gene expression 
(Figure 2c, middle and right panels). These findings collectively demonstrate the role of UEV1A in promoting OS differentiation.

Uevs (Uev1 and Mms2) lack the active site Cys residue found in Ubcs and their only known activity to date is a cofactor required for Ubc13-catalyzed Lys63 poly-Ub chain formation. ${ }^{18,19}$ Surprisingly, Dox-induced UBC13 overexpression failed to elevate the expression of differentiation markers (Figure 2d), although it was able to strongly enhance nuclear translocation of p65 as expected (Supplementary Figures S2a and $b$ ). To further address whether UEV1A-induced OC cell differentiation is dependent on Ubc13, we made a Uev1AF38E (labeled as Uev1Am) mutation that abolishes its physical interaction with Ubc13 ${ }^{26}$ (Figure S2c). Overexpression of UEV1Am (Supplementary Figure S2d) resulted in an even stronger differentiation marker expression than that of UEV1A (Figure 2e), confirming that Uev1A promotes U2OS differentiation in an Ubc13-independent manner.

UEV1A overexpression relieves BMP-induced inhibition of differentiation. It has been well established that bone morphogenesis proteins (BMPs) inhibit osteoblast differentiation through transcriptional activation of IDs. ${ }^{9,10,27}$ As UEV1A promotes OS cell differentiation, it would be of interest to see its effects on BMP-induced differentiation block. An ICC assay (Figure $3 a$ ) and qRT-PCR (Figure $3 b$ ) confirmed that UEV1A overexpression inhibited the expression of ID genes. As expected, ${ }^{8}$ treatment of U2OS cells with BMP2 induced the $I D$ gene expression while repressed $R U N X 2, O C$ and SPP1 (Figure 3c). Under the above experimental conditions, ectopic expression of UEV1A diminished the effect of BMP2 on $I D$ genes (Figure $3 b$ ) and meanwhile partially relived the inhibitory effect of BMP2 on RUNX2 and OC (Figure 3c). We conclude from the above observations that Uev1A promotes OS differentiation by serving as a negative regulator of the BMP pathway.

UEV1A overexpression suppresses oncogene expression and inhibits the CSC status of OS cells. As BMP treatment has been reported to enhance OS tumor growth, ${ }^{8}$ we speculated that Uev1A could serve as an OS inhibitor through promoting OS differentiation. As the first step toward understanding the role of UEV1A in tumor inhibition, we examined the effects of UEV1A overexpression on several oncogenes known to be highly expressed in OS cells. ${ }^{28}$ Compared with the control, Dox-induced UEV1A reduced $M Y C$ and $C D K 4$ expression by $>50 \%$ (Figures $4 a$ and $b$ and Supplementary Figure $\mathrm{S} 3 \mathrm{a}$ ) and this effect appears to be specific for UEV1A, as ectopic expression of UEV1C, MMS2 or UBC13 did not cause such consistent reduction (Figure 4a). We also screened other OS-related oncogenes and confirmed the role of UEV1A in repressing their expression (Supplementary Figure S3b). The activities of C-Myc and aldehyde dehydrogenase 1 (Aldh1) have been used to define enhanced tumorigenesis and stem cell properties of cancers. ${ }^{29,30}$ Upon UEV1A induction, cellular C-Myc and Aldh1 levels were also markedly reduced (Figure $4 \mathrm{~b}$ and Supplementary Figures S3a and c). To further explore the biological role of Uev1A in OS, we measured cell proliferation upon UEV1A overexpression and found that it markedly decreased tumor cell growth (Figure 4c).

Expression of stem cell marker genes has been taken as evidence of CSCs in OS. ${ }^{12,13}$ Upon Dox induction of UEV1A expression, not only was tumorigenic marker gene expression decreased, the cellular protein levels of Oct4 and Sox2, two classic stem cell markers, were also reduced (Figure 4d and Supplementary Figures S3d and e). Elevated expression of stem cell markers has been taken to explain why $O S$ is refractory to chemotherapy. ${ }^{1,2}$ To examine whether UEV1A overexpression can sensitize OS cells to chemotherapy, we treated U2OS cells with low doses of an anticancer drug adriamycin (ADM) in the presence or absence of ectopic UEV1A expression and examined their effects on CDK4 expression as an indicator of cell cycle progression. ${ }^{31,32}$ Although $1 \mu \mathrm{g} / \mathrm{ml}$ ADM treatment or UEV1A overexpression alone reduced the CDK4 transcript level by approximately $20 \%$, the combined treatments resulted in a synergistic reduction of $C D K 4$ expression by $80 \%$ (Figure $4 \mathrm{e}$ and Supplementary Figure S3f). Although overexpression of UEV1A alone had little effect on cell death, it markedly enhanced lowdose ADM-induced cell death from $<3$ to $10 \%$ (Figure $4 \mathrm{f}$ ), indicating that UEV1A expression can indeed sensitize OS cells to effective chemotherapy. We conclude from the above observations that Uev1A promotes OS differentiation, inhibits the stem cell properties of OS and sensitizes OS cells to chemotherapy.

Uev1A promotes Smurf1-mediated Smad1 degradation. BMP signal transduction requires receptor-regulated Smads (R-Smads, including Smad1, 5 and 8), which translocate into the nucleus as transcriptional regulators. ${ }^{33-35}$ As the activity of R-Smads is primarily regulated by the ubiquitination-26S proteasome system, ${ }^{36}$ we examined cellular Smad levels in response to UEV1A expression in the presence of cycloheximide $(\mathrm{CHX})$ that inhibits de novo protein synthesis. UEV1A overexpression specifically promotes Smad1 but not Smad5 or Smad8 (Figure 5a) degradation over time. Under the same experimental conditions, neither UEV1C nor MMS2 promoted Smad1 degradation (Figure 5b). Notably, overexpression of UEV1Am also promotes Smad1 degradation at a rate faster than that of UEV1A (Figure 5a), whereas UBC13 has no such an effect (Figure $5 \mathrm{~b}$ ), consistent with a notion that Uev1A targets Smad1 degradation in a Ubc13-independent manner.

Although Ubc13 is not involved in the Smad1 degradation, the Uev1A-induced Smad1 degradation is mediated by the ubiquitination-26S proteasome system, as treatment of UEV1A or UEV1Am expressed cells with a $26 \mathrm{~S}$ proteasome inhibitor MG132 prevented Smad1 degradation (Figure 5c). Smurf1, a HECT-containing E3, is known to trigger ubiquitination of Smad1, 5, 8 and destines them for proteasomemediated degradation. ${ }^{37}$ To establish a relationship between Uev1A and Smurf1 in the Smad1 degradation, we first confirmed the role of Smurf1 in degrading Smad1 similar to that of UEV1A overexpression (Supplementary Figure S4a). Importantly, when Smurf1 was depleted by siRNA in UEV1Aor UEV1Am-overexpressed U2OS cells (Figure 5d), Smad1 was no longer degraded over time (Figure 5e), indicating that Smurf1 is absolutely required to mediate Uev1A-induced 
a
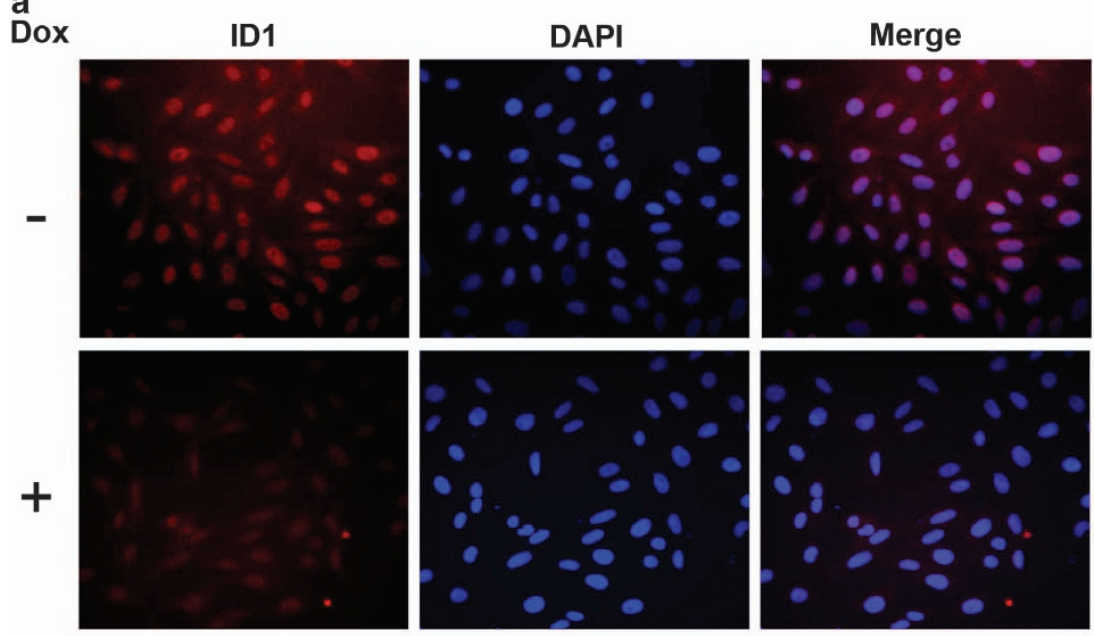

b

ID1

ID2

ID2
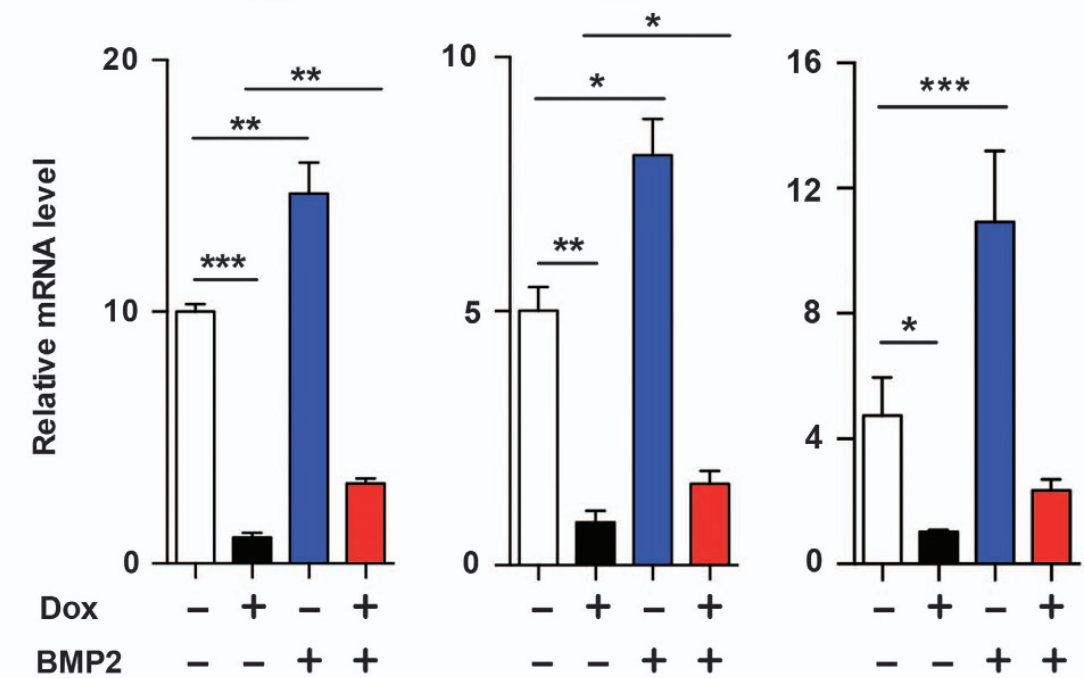

C

RUNX2 SPP1

oc

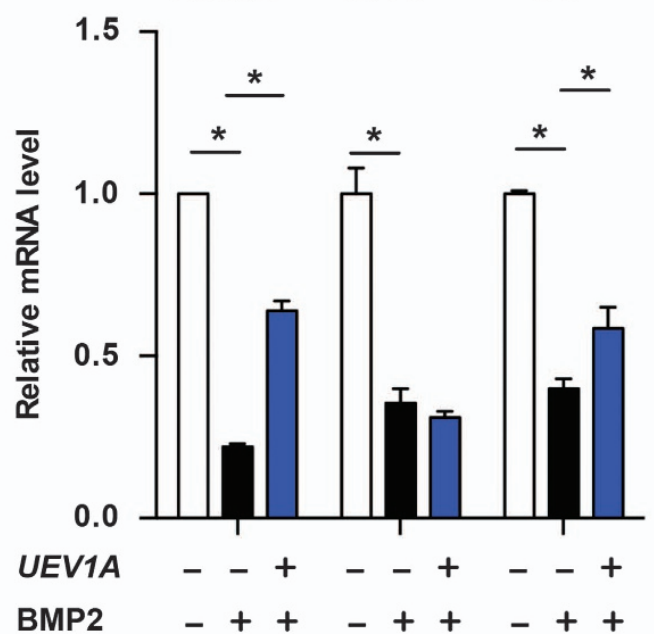

Figure 3 UEV1A overexpression antagonizes BMP2 for OS cell differentiation. (a) UEV1A overexpression suppresses ID1 as judged by ICC. Representative images of several independent experiments are presented. (b) UEV1A overexpression inhibits BMP-induced expression of ID genes. Stable U2OS transfectants harboring Dox-inducible UEV1A in the presence or absence of Dox was untreated or treated with BMP2 for 4 weeks. Total RNAs were harvested for qRT-PCR analysis. (c) UEV1A overexpression inhibits BMP-repressed differentiation marker genes. The experiment procedure was as described in (b) 

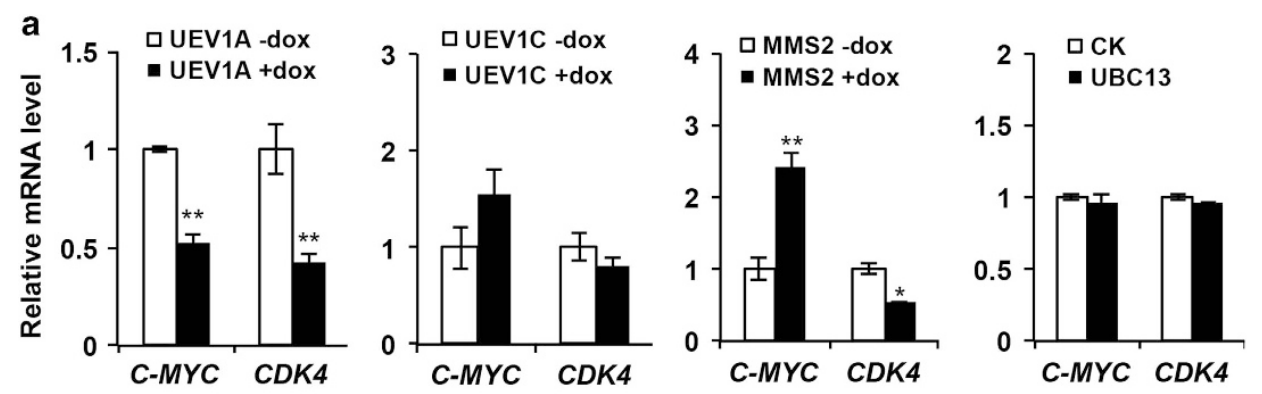

b
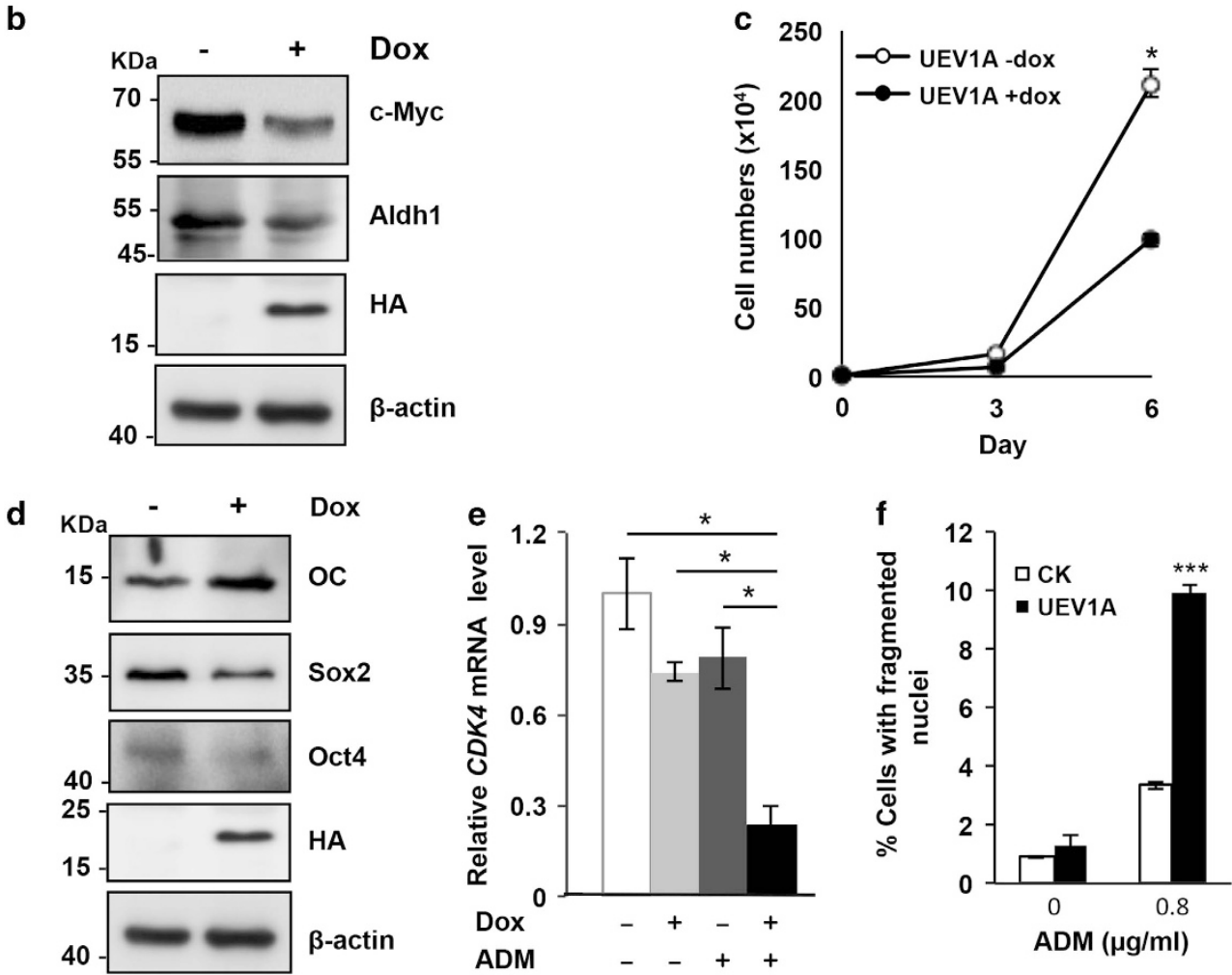

Figure 4 UEV1A overexpression inhibits OS-related proto-oncogene and stem cell marker gene expression and cell proliferation. (a) Effects of ectopic UEV gene expression on the expression of OS-related proto-oncogenes. Total RNA was extracted from control and UEV-overexpressed cells followed by qRT-PCR analysis. Data are presented as the mean \pm S.D. (b) WB analysis of c-Myc and Aldh1 levels. (c) UEV1A overexpression reduces U2OS cell proliferation. After stably transfected U2OS cells were treated with Dox for 4 weeks, collected cells were seeded in the $6 \mathrm{D}$ plate with fresh Dox-containing medium and incubated for the indicated period before cell counting. The Dox-population followed the same treatment except adding Dox. (d) Ectopic UEV1A expression reduces cellular Sox2 and Oct4 levels as revealed by WB. (e) Synergistic effects of ectopic UEV1A expression and ADM treatment on CDK4 expression. Total RNAs were extracted for the qRT-PCR analysis and results are presented as mean \pm S.D. (f) UEV1A overexpression sensitizes U2OS cells to the anticancer agent ADM. The UEV1A-transfected cells were untreated or treated with $0.8 \mu \mathrm{g} / \mathrm{ml}$ ADM for $48 \mathrm{~h}$. UEV1A-transfected U2OS cells without Dox induction were used as a control

Smad1 degradation and hence Uev1A and Smurf1 belong to the same signaling pathway.

Uev1A enhances UbcH5B-Smurf1 ubiquitination of Smad1 through physical interaction with Smurf1. The above observations suggest that Smurf1 acts as a E3 to mediate Uev1A-promoted OS differentiation and tumor growth. Indeed, in a reconstituted ubiquitination assay, Uev1A itself could not serve as an E2 to mediate Smad1 ubiquitination (Figure 6a, lane 2); however, when UbcH5B, a known Smurf1-interacting E2, ${ }^{38}$ was added along with Smurf1, smear bands characteristic of Smad1 polyubiquitination were observed (lane 3). Moreover, Uev1A markedly increased the intensity of the polyubiquitination chains in a Smurf1-dependent manner (Figure 6a, lanes 4, 5 and 6). In addition, gradually increasing amounts of Uev1a in the reaction resulted in correspondingly enhanced signal of ubiquitinated Smad1 (Figure 6b). Collectively, we concluded that Uev1A is a cofactor of the E2-E3 complex UecH5BSmurf1 that promotes Smad1 ubiquitination and subsequent degradation, leading to OS differentiation and inhibition of tumor growth.

Uev1A and Mms2 belong to a family of Ubc-E2 variants ${ }^{39}$ known to function as a cofactor of Ubc13. ${ }^{19,21}$ We first asked in the above ubiquitination reaction, whether Uev1A also functions as a cofactor of UbcH5B. Under conditions of 
a
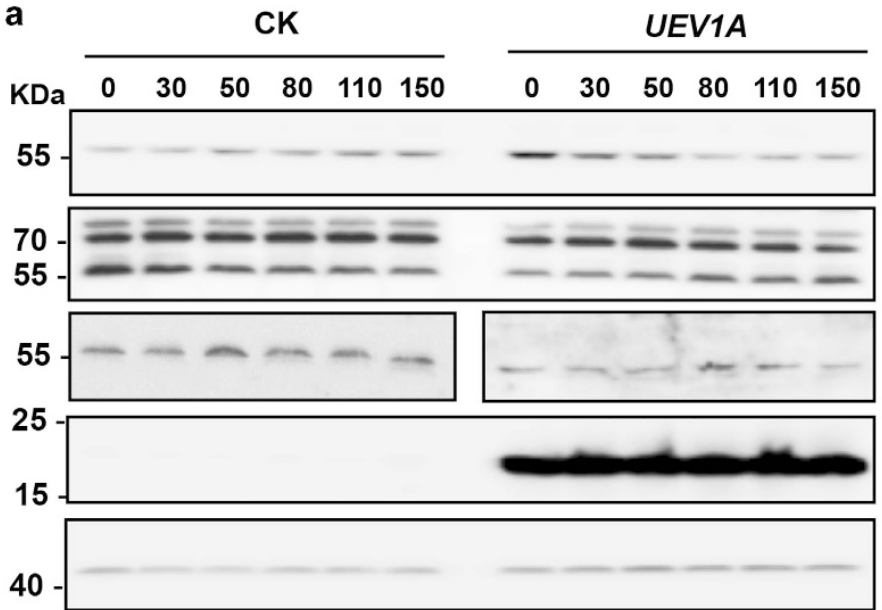

b

b UEV1C
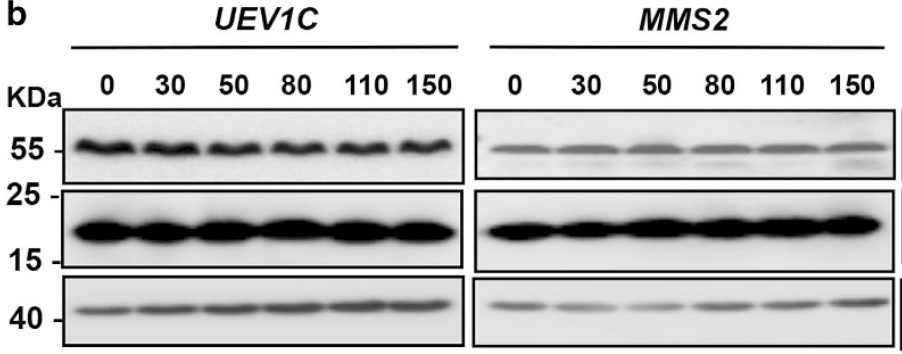

c
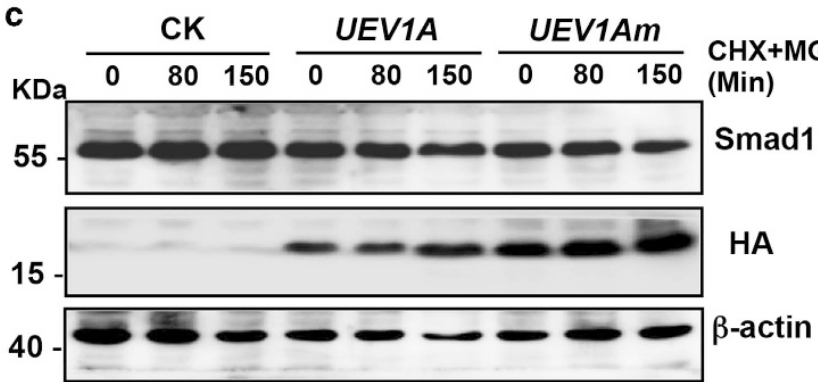

(Min)

Smad1

HA

-actin

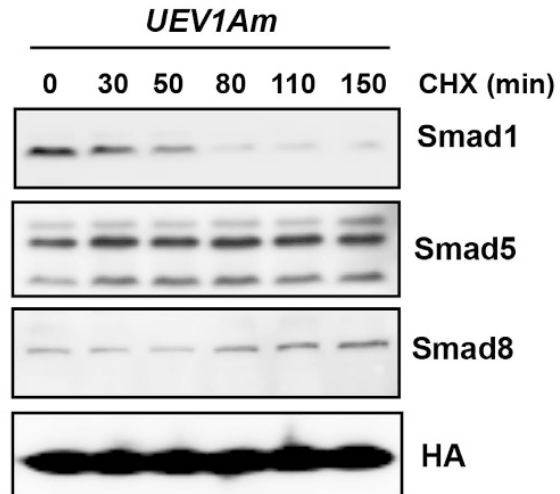

$\beta$-actin

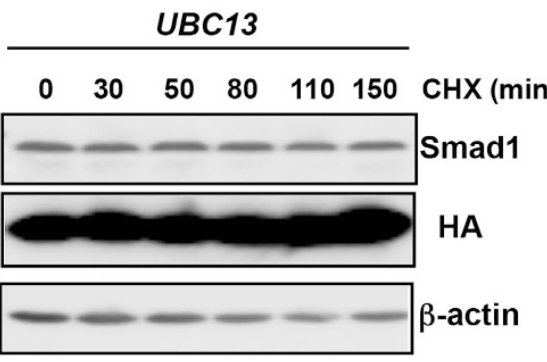

e

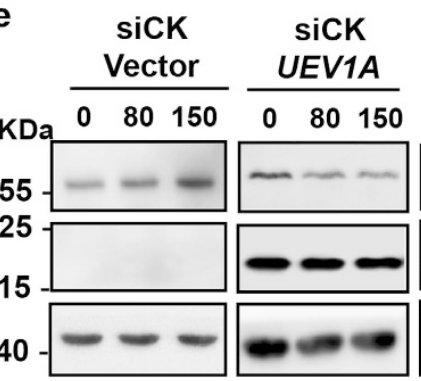

siCK SISMURF1 SiSMURF1 UEV1Am UEV1A UEV1Am \begin{tabular}{llllll}
\hline 0 & 80 & 150 & 0 & 80 & 150
\end{tabular} $0 \quad 80150 \mathrm{CHX}$ (min)
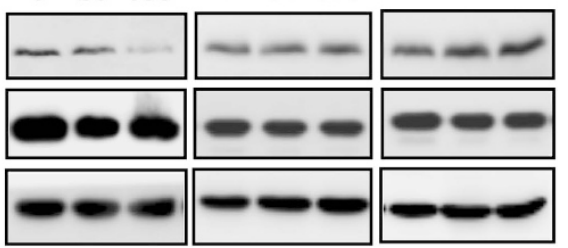

Smad1

HA

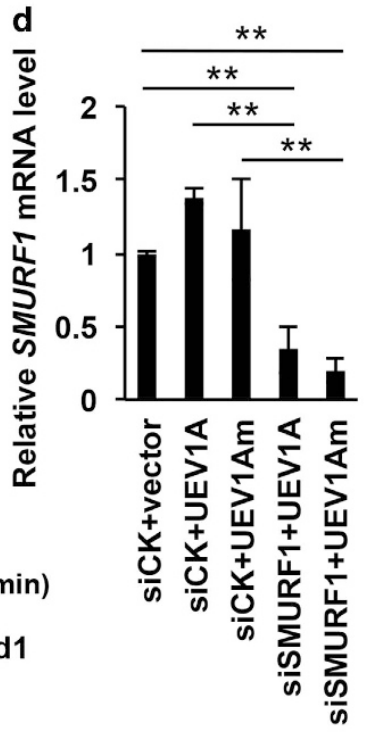

Figure 5 WB analyses of Smad1 stability in the presence of de novo protein inhibitor CHX. (a-e) U2OS cells were transfected with constructs expressing HA-tagged UEVs. Four days after transfection, the cells were treated with $10 \mu \mathrm{g} / \mathrm{ml} \mathrm{CHX}$ for the indicated time. Equal amounts of cell extracts were subjected to SDS-PAGE. The related protein levels were examined by WB against indicated antibodies. (a) Ectopic expression of either UEV1A or UEV1Am reduces the cellular Smad1 level, but not Smad5 or Smad8. (b) Ectopic expression of UEV1C, MMS2 or UBC13 does not affect Smad1 stability. (c) Smad1 is destabilized by the ubiquitination-26S proteasome degradation system, as treatment of cells with a $26 S$ proteasome inhibitor prevents Uev1A-induced Smad1 degradation. (d) Depletion of cellular Smurf1 by siRNA. The relative SMURF1 transcript level was measured by qRT-PCR following siRNA treatment. (e) Uev1A-mediated Smad1 degradation depends on Smurf1. siRNA against SMURF1 was transfected into the HAtagged UEV1A- or mUEV1A-overexpressed U2OS cells. Three days after transfection, the cells were treated with $10 \mu \mathrm{g} / \mathrm{ml} \mathrm{CHX}$ for the indicated time points. Equal amount of cell extracts was subjected to SDS-PAGE and WB analysis 


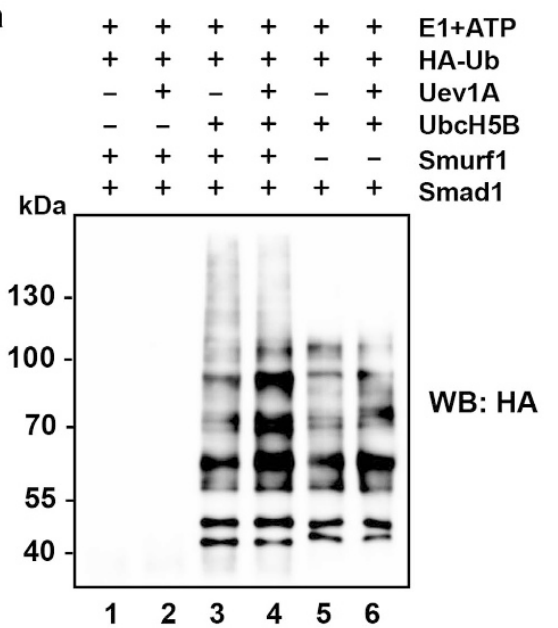

b

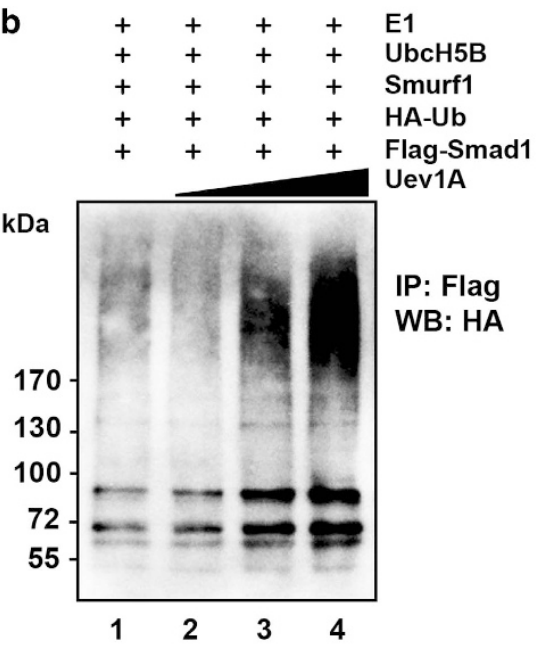

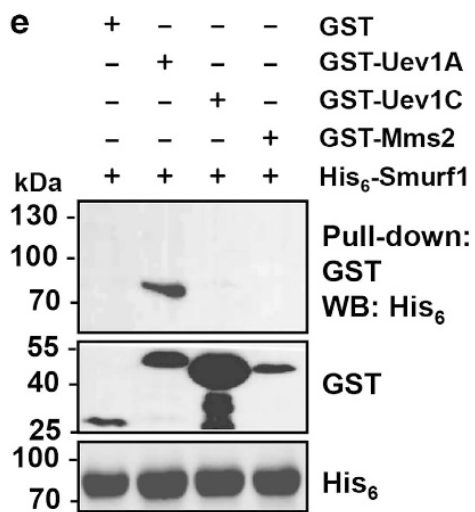

$70-\mathrm{His}_{6}$
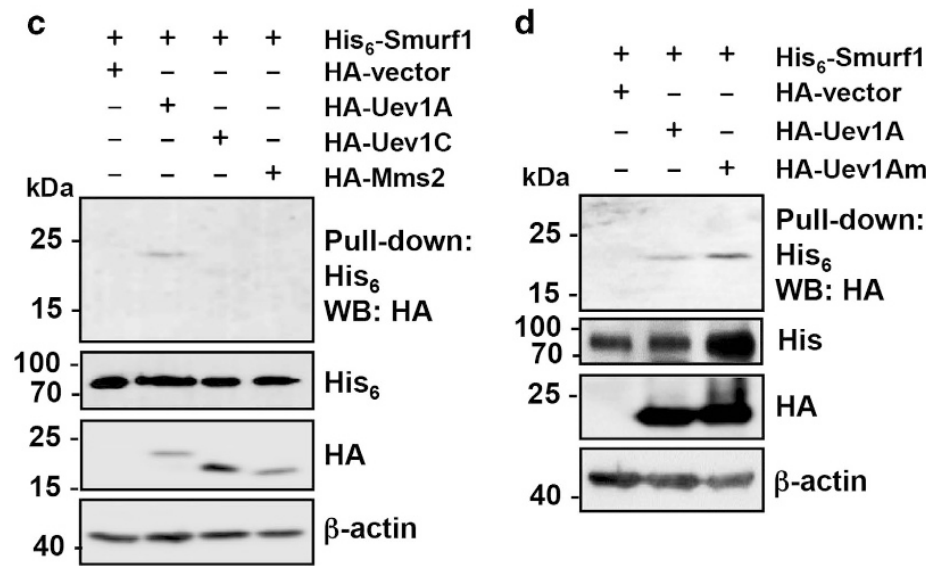

Figure 6 Uev1A interacts with Smurf1 and promotes UbcH5B-Smurf1 ubiquitination of Smad1. (a) Uev1A can enhance Smad1 polyubiquitination by UbcH5B-Smurf1 in an in vitro ubiquitination assay. Purified components as indicated on the top panel were added in an ubiquitination assay reaction, which was stopped and the products were separated by SDS-PAGE and probed against an HA antibody. (b) In vitro ubiquitination assay showing the critical role of Uev1A in the process of Smurf1-mediated Smad1 polyubiquitination. Different amounts $(10,20$ and $40 \mathrm{nM})$ of purified Uev1A proteins were used for the reaction. Experimental conditions were as described and the reaction products were immunoprecipitated by anti-Flag beads before WB. (c) A His $s_{6}$ pull-down assay showing the interaction between Smurf1 and Uev1A. His ${ }_{6}$-tagged Smurf1 protein was purified from bacterial cells and bound to the Nickel beads. Whole-cell extracts from HA-tagged UEV-expressing U2OS cells were mixed and incubated with the beads. The elution was subjected to WB by using anti-HA and anti-actin antibodies. Anti-His ${ }_{6}$ antibody was used to show the equal amount of Smurf1 protein was used for the pull-down assay. (d) Both Uev1A and Uev1Am were co-purified with $\mathrm{His}_{6}$-Smurf1. Experimental conditions were as described in c. (e) A GST pull-down assay showing the direct interaction between Uev1A and Smurf1. GST-tagged Uevs were purified and bound to the GST affinity beads. His $s_{6}$ tagged Smurf1 was purified and mixed with the beads. Elution was further subjected to western blotting assay by using anti-GST and anti-His ${ }_{6}$ antibodies

Uev1A-Ubc13 interaction, Uev1A does not appear to bind UbcH5B (Supplementary Figure S4b). We then asked whether Uev1A could serve as a cofactor for Smurf1. In a $\mathrm{His}_{6}$-affinity pull-down assay, $\mathrm{His}_{6}$-tagged Smurf1 interacted with HA-tagged Uev1A, but not Uev1C or Mms2, from total cell extract (Figure $6 \mathrm{c}$ ). This interaction does not appear to require Ubc13, as HA-Uev1Am was also co-purified with $\mathrm{His}_{6}$-Smurf1, and the stronger signal of Uev1Am than Uev1A (Figure 6d) was either because of an increased expression level of UEV1Am over UEV1A or the fact that Uev1Am does not bind to Ubc13 for other cellular functions. To address whether Uev1A-Smurf1 interaction is direct, a pull-down assay was performed using bacterially purified proteins. As shown in Figure 6e, GST-tagged Uev1A, but not GST-Uev1C or GSTMms2, was able to pull-down $\mathrm{His}_{6}-$ Smurf1, confirming the direct interaction between Uev1A and Smurf1. To further confirm the involvement of Smurf1 and UbcH5B in the differentiation of U2OS cells, we overexpressed SMURF1 or UBCH5B, or depleted cellular Smad1 by siRNA. In all three cases, significant elevation of some OC differentiation marker gene expression was observed (Supplementary Figures S4c-h).

To ask whether the above-observed effects are a general phenomenon in OS cells, we repeated several critical experiments in another OS cell line SaoS2. Overexpression of UEV1A caused Smad1 degradation in SaoS2 cells (Supplementary Figure S5a). Similarly, overexpression of UEV1A, UEV1Am (Supplementary Figure S5b) or UBCH5B (Supplementary Figures S5c and d) induced differentiation marker genes in SaoS2 cells, indicating that this signaling pathway is conserved in OS cells. 


\section{Discussion}

In summary, one of the key findings in this study is Uev1Amediated regulation of the BMP pathway where it cooperates with a novel E2-E3 partner UbcH5B-Smurf1 to control cell differentiation. A working model based on findings in this study and previous reports is depicted in Figure 7. This study reveals a critical role of Uev1A in promoting osteoblast differentiation and preventing OS. It also demonstrates that the enhanced Uev1A activity may serve as a means of treating OS. Before this report, eukaryotic Uevs (including Mms2 and Uev1) are only known to function as a partner of Ubc13 to promote K63linked polyubiquitination. ${ }^{18,19}$ Ubc13-Uev heterodimers have been attributed to different biological functions, in which Uevs confer certain selectivity. ${ }^{21}$ Surprisingly, in this study Uev1Amediated Smad1 polyubiquitination is independent of Ubc13, consistent with a notion that Smad1 polyubiquitination leads to its degradation by the $26 \mathrm{~S}$ proteasome, ${ }^{36,40}$ whereas Ubc13Uev mediated K63-polyubiquitination often does not degrade target proteins but alters its cellular function. ${ }^{41}$

Uevs bind to Ubc13 via a unique key-keyhole structure only found in Ubc13s across the entire eukaryotic kingdom. ${ }^{26}$ Apparently this interaction does not apply to Uev1A and UbcH5B. This study reveals that Uev1A directly binds Smurf1 in vitro and in vivo, and this physical interaction must require its $\mathrm{N}$-terminus, as neither Uev1C nor Mms2 can bind Smurf1. The cognate E3s for Ubc13-Uev to date include RING finger proteins TRAF2/6, TRIM5, budding yeast Rad5 and its mammalian homologs SHPRH and HLTF, and a U-boxcontaining CHIP, all of which directly interact with Ubc13 and are involved in K63-linked polyubiquitination. In contrast, Smurf1 is a HECT domain-containing E3 involved in regulating the BMP pathway through ubiquitination of Smads. ${ }^{42}$ Although both CHIP and Smurf1 are capable of promoting Smad protein degradation through ubiquitination, CHIP-mediated regulation appears to be independent of BMP stimulation, whereas Smurf1 is tightly controlled by the BMP signaling. ${ }^{37,43,44}$

Another striking finding in this study is that Uev1A serves as a novel OS repressor. It is capable of suppressing OS-related oncogenes, reducing the stem cell property and sensitizing

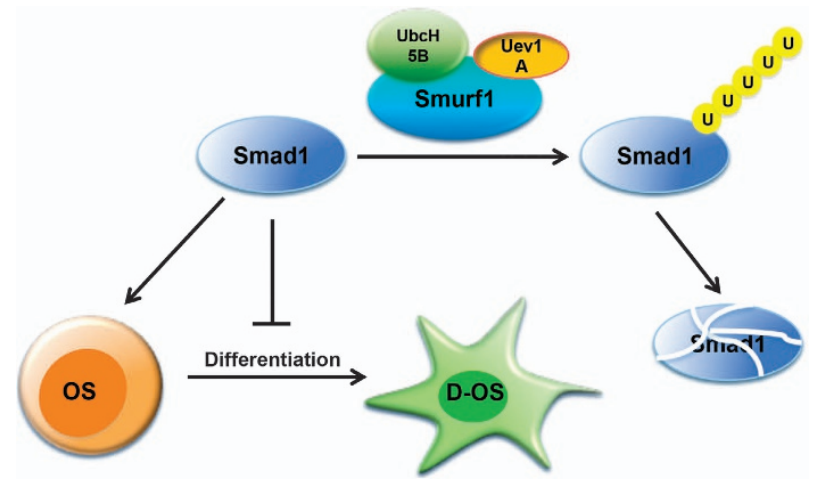

Figure 7 A working model for the role of Uev1A in promoting OS differentiation and thus repressing tumor growth. Uev1A cooperated with UbcH5B and Smurf1 to mediate Smad1 polyubiquitination and its subsequent degradation. This activity drives OS cells to terminal differentiation, which inhibits tumor cell proliferation and sensitizes OS cells to chemotherapy
OS cells to chemotherapy. These findings collectively point Uev1A as a promising clinic target for OS therapy. This is in sharp contrast to generally conceived roles of Uev1A in tumorigenesis, as previous studies assign UEV1A as a putative proto-oncogene. ${ }^{22,45}$ This is primarily because the Ubc13-Uev1A complex is required for the innate immunity by sensing and activating $\mathrm{NF}-\mathrm{KB}^{20,46,47}$ and possibly other signaling pathways, ${ }^{48}$ and a constitutive UEV1A overexpression has been associated with tumorigenesis in several types of cancers. Of particular note is a previous report implying negative correlation between the Uev1 level and colon carcinoma cell differentiation. ${ }^{17}$ We envisage that the biological function of Uev1A should be determined by signaling pathways that it regulates in the given tissue. In this study, Uev1A-promoted OS cell differentiation and the consequent tumor suppression is through inhibiting the unique BMP pathway in OS cells in a Ubc13-independent manner. Hence, it will be of great interest to explore roles of Uev1A in differentiation in other types of cancers.

\section{Materials and Methods}

Cell culture. Human U2OS cells (ATCC, Manassas, VA, USA) were cultured at $37{ }^{\circ} \mathrm{C}$ with $5 \% \mathrm{CO}_{2}$. The cells were maintained in Dulbecco's modified Eagle's medium (DMEM; GIBCO, Grandlsland, NY, USA), supplemented with $10 \%$ fetal bovine serum (FBS; GIBCO) and 5000 units/ml penicillin/streptomycin (Chemicon, Belmopán, Belize, USA).

Osteogenic differentiation. Seed U2OS cells at the density of $5 \times 10^{4}$ cells/ $\mathrm{cm}^{2}$ in culture plates with DMEM supplemented with $10 \%$ FBS. After $24 \mathrm{~h}$, the culture medium was changed with osteogenic media (DMEM supplemented with $10 \%$ FBS, $0.1 \mu \mathrm{M}$ dexamethasone (Sigma, St. Louis, MO, USA), $10 \mathrm{mM} \beta$ glycerophosphate (Sigma) and $50 \mu \mathrm{M}$ ascorbate phosphate (Sigma)) to induce U2OS cell differentiation. The culture medium was changed every other day.

Protein extraction and western blotting. Total protein was extracted by lysing cells with the whole cell extraction buffer $(50 \mathrm{mM}$ Tris- $\mathrm{HCl}, 150 \mathrm{mM} \mathrm{NaCl}, 1 \%$ NP40, 10\% glycerol, 1 mM EDTA and 1 mM PMSF). Thirty micrograms of the total protein was separated by SDS-PAGE and transferred to PVDF membrane. The membrane was blocked with $5 \%$ milk and probed with specific primary and secondary antibodies. The blots were developed with ECL Advance Western Blotting Detection Kit (Amersham, Sweden). The following antibodies were used: anti-OC (Santa Cruz, Dallas, TX, USA, sc-18319), anti-Smad1 (Cell Signaling, Danvers, MA, USA, 9743 S), anti-Smad5 (Abcam, Cambridge, MA, USA, ab13724), anti-Smad8 (Santa Cruz, sc-11393), anti-Oct4 (Santa Cruz, sc-8628), anti-Sox2 (Santa Cruz, sc-17320), anti-HA (Santa Cruz, sc-7392), anti-Flag (Sigma, F1804) and anti- $\beta$-actin. A monoclonal antibody LN3 was made in-house by using purified Uev1A as an antigen, and its epitope recognition region was mapped to amino acids 31-44 with a sequence GVKVPRNFRLLEEG, which is identical to that in Uev1C and Mms2. Hence, LN3 recognizes all three Uevs in this study.

His6 and GST pull-down assays. For the His pull-down assay, purified His6-tagged Smurf1 fusion protein was pre-cleared with immobilized nickel agarose beads (GE Healthcare, Pittsburg, PA, USA) for $1 \mathrm{~h}$ and incubated with the cell extract overexpressing HA-tagged Uev1A, Uev1A-F38E (mUev1A), Uev1C or Mms2 overnight at $4{ }^{\circ} \mathrm{C}$. Protein-bound beads were washed five times with a lysis buffer and eluted in an SDS-PAGE sample buffer. Eluted proteins were analyzed by immunoblotting. For the GST pull-down assay, purified GST-tagged Uev1A, Uev1C or Mms2 fusion proteins were pre-cleared with GST beads (GE Healthcare, 170756-0) for $1 \mathrm{~h}$ and incubated with purified His6-tagged SMURF1 overnight at $4{ }^{\circ} \mathrm{C}$. Protein-bound GST beads were washed four times with the lysis buffer and eluted in the SDS-PAGE sample buffer. Eluted proteins were analyzed by immunoblotting.

Immunocytochemistry. Cells were fixed with $4 \%$ formaldehyde for $30 \mathrm{~min}$, washed four times over 30 min with PBS plus $0.25 \mathrm{~g}$ Tween 20 (PBST) and blocked with $5 \%$ horse serum in PBST. Primary anti-Uev1A (homemade), anti-Oct4 (Santa 
Cruz, SC-8628 1:250), anti-Sox2 (Santa Cruz sc-17320, Fremont, CA, USA, 1:250), anti-C-Myc (Calbiochem OP10, Belmopán, Belize, USA, 1:400), anti-CDK4 (Neomarkers MS-469, Belmopán, Belize, USA, 1:200) and anti-ALDH1 (Abcam ab-6192, 1:500) antibodies were applied in blocking solution for $1 \mathrm{~h}$. After washing in PBST, coverslips were incubated with Alexa546-conjugated anti-mouse (Molecular Probes, 1:3000) and Alexa488-conjugated anti goat (Molecular Probes, Waltham, MA, USA, 1:2000) secondary antibodies for $20 \mathrm{~min}$ in the presence of DAPI $(2 \mu \mathrm{g} / \mathrm{ml})$ for $20 \mathrm{~min}$ before washing again with PBST and mounting. Images were captured with a $20 x$ oil emersion objective lens, and all red and green images were adjusted identically in order to generate the merge images.

To assess NF-kB activation, cells grown in a slide were transfected with pCMV-3xFlag- UBC13 or the empty vector. After incubation for $48 \mathrm{~h}$, cells were fixed in $4 \%$ paraformaldehyde solution (Affymetrix, Waltham, MA, USA) for $20 \mathrm{~min}$ at room temperature, permeabilized with $0.4 \%$ Triton X-100, blocked in 5\% FBS and then incubated with mouse anti-Flag (Sigma, F1804, 1:1000) and rabbit against the p65 subunit of NF-KB (Santa Cruz, sc-372, 1:1000) antibodies overnight at $4{ }^{\circ} \mathrm{C}$. Only Flag-positive cells were counted for the nuclear enrichment of $p 65$.

RNA isolation, reverse transcription and real-time RT-PCR (qRT-PCR) analysis. Total RNA was extracted using Trizol reagent (Invitrogen, Grand Island, NY, USA). cDNA synthesis was performed with $500 \mathrm{ng}$ of total RNA using RevertAid First Strand cDNA Synthesis kit (Fermentas, Waltham, MA, USA) according to the manufacturer's instructions. Endogenous mRNA levels were measured by qRT-PCR analysis based on SYBR Green detection (Fermentas) with the Bio-Rad (Hercules, CA, USA) real-time PCR machine. Results were normalized with $\beta$-actin (t-test: ${ }^{* * \star} P<0.0001$; ${ }^{* * \star} P<0.005$; ${ }^{* \star} P<0.01$; ${ }^{*} P<0.05$; ns: no significance). All the primers used in the study gave rise to single product of the expected size in agarose gel analysis.

In vitro ubiquitination assays. A $0.5-\mathrm{ml}$ conjugation reaction containing $250 \mathrm{nM}$ Uba1, $600 \mu \mathrm{M}$ Ub, $500 \mathrm{nM}$ Uev1A, $1 \mu \mathrm{M}$ Smurf1, $500 \mathrm{nM}$ UbcH5B and $200 \mathrm{nM}$ Smad1 in an ATP cocktail (10 mM Hepes, pH7.5, $5 \mathrm{mM} \mathrm{MgCl}, 5 \mathrm{mM}$ ATP and $0.6 \mathrm{U} / \mathrm{ml}$ inorganic phosphatase) was incubated at $30^{\circ} \mathrm{C}$ for $90 \mathrm{~min}$. Reactions were terminated by the addition of TCA to a final concentration of $10 \%$ and processed for a 12\% SDS-PAGE analysis with antibodies against HA (Santa Cruz, sc-7392). To assess the level of Smad1 ubiquitination, conjugation reactions were conducted as above except that the ATP cocktail does not contain inorganic phosphatase and the reaction was terminated by $5 \% \beta$-mercaptoethanol. The above product was incubated with anti-Flag magic beads (Sigma, M8823) overnight at $4{ }^{\circ}$ C. Protein-bound beads were washed five times with a lysis buffer and eluted in an SDS-PAGE sample buffer. Eluted proteins were analyzed by immunoblotting with rabbit anti-HA antibodies (Bethyl, Montgomery, TX, USA, A190-208 A, 1:5000).

Significance. Uev1A has been previously shown to promote tumorigenesis and metastasis via the NF-kB and possibly other signaling pathways, while this study identifies UEV1A as a putative tumor suppressor in OS cells. Furthermore, all known functions of the Uev family proteins to date are to serve as a cofactor of Ubc13 to promote K63-linked polyubiquitination, while this study shows that the newly identified Uev1A function is independent of Ubc13, which opens a door to Uev family functions beyond the conventional Ubc13 pathway. This study offers a novel means of inducing OS cell differentiation and hence may shed light to the future cure of OS.

\section{Conflict of Interest}

The authors declare no conflict of interest.

Acknowledgements. This work was supported by a Capital Normal University start-up Fund (043145303300) and a Chinese National 973 Program (2013CB911003) to WX, and a Natural Science Foundation of China grant (31101055) to WZ.

\section{Author contributions}

WZ: conception, design, data analysis, interpretation and manuscript writing. YZ: collection and assembly of data, data analysis and interpretation; YZ, XY, HZ, GW, WY, RW and ZZ: collection and/or assembly of data and data analysis. WX: conception, design, financial support and manuscript writing.

\section{Publisher's Note}

Springer Nature remains neutral with regard to jurisdictional claims in published maps and institutional affiliations.

1. Meyers PA, Gorlick R. Osteosarcoma. Pediatr Clin North Am 1997; 44: 973-989.

2. Kaste SC, Pratt CB, Cain AM, Jones-Wallace DJ, Rao BN. Metastases detected at the time of diagnosis of primary pediatric extremity osteosarcoma at diagnosis: imaging features. Cancer 1999; 86: 1602-1608.

3. Gorlick R, Anderson P, Andrulis I, Arndt C, Beardsley GP, Bernstein M et al. Biology of childhood osteogenic sarcoma and potential targets for therapeutic development: meeting summary. Clin Cancer Res 2003; 9: 5442-5453.

4. Kempf-Bielack B, Bielack SS, Jurgens H, Branscheid D, Berdel WE, Exner GU et al. Osteosarcoma relapse after combined modality therapy: an analysis of unselected patients in the Cooperative Osteosarcoma Study Group (COSS). J Clin Oncol 2005; 23: 559-568.

5. Marina N, Gebhardt M, Teot L, Gorlick R. Biology and therapeutic advances for pediatric osteosarcoma. Oncologist 2004; 9: 422-441.

6. Haydon RC, Luu HH, He TC. Osteosarcoma and osteoblastic differentiation: a new perspective on oncogenesis. Clin Orthop Relat Res 2007; 454: 237-246.

7. Thomas DM, Johnson SA, Sims NA, Trivett MK, Slavin JL, Rubin BP et al. Terminal osteoblast differentiation, mediated by runx2 and p27KIP1, is disrupted in osteosarcoma. $J$ Cell Biol 2004; 167: 925-934.

8. Luo X, Chen J, Song WX, Tang N, Luo J, Deng ZL et al. Osteogenic BMPs promote tumor growth of human osteosarcomas that harbor differentiation defects. Lab Invest 2008; 8 : 1264-1277.

9. Peng Y, Kang Q, Cheng H, Li X, Sun MH, Jiang W et al. Transcriptional characterization of bone morphogenetic proteins (BMPs)-mediated osteogenic signaling. J Cell Biochem 2003; 90: 1149-1165.

10. Peng $Y$, Kang $Q$, Luo Q, Jiang W, Si W, Liu BA et al. Inhibitor of DNA binding/differentiation helix-loop-helix proteins mediate bone morphogenetic protein-induced osteoblast differentiation of mesenchymal stem cells. J Biol Chem 2004; 279: 32941-32949.

11. Ducy $P$, Schinke $T$, Karsenty $G$. The osteoblast: a sophisticated fibroblast under central surveillance. Science 2000; 289: 1501-1504.

12. Wang L, Park P, Lin CY. Characterization of stem cell attributes in human osteosarcoma cell lines. Cancer Biol Ther 2009; 8: 543-552.

13. Levings PP, McGarry SV, Currie TP, Nickerson DM, McClellan S, Ghivizzani SC et al. Expression of an exogenous human Oct-4 promoter identifies tumor-initiating cells in osteosarcoma. Cancer Res 2009; 69: 5648-5655.

14. Reya T, Morrison SJ, Clarke MF, Weissman IL. Stem cells, cancer, and cancer stem cells. Nature 2001; 414: 105-111.

15. Wicha MS, Liu S, Dontu G. Cancer stem cells: an old idea-a paradigm shift. Cancer Res 2006; 66: 1883-1890.

16. Broomfield S, Chow BL, Xiao W. MMS2, encoding a ubiquitin-conjugating-enzyme-like protein, is a member of the yeast error-free postreplication repair pathway. Proc Natl Acad Sci USA 1998; 95: 5678-5683.

17. Sancho E, Vila MR, Sanchez-Pulido L, Lozano JJ, Paciucci R, Nadal M et al. Role of UEV-1, an inactive variant of the $\mathrm{E} 2$ ubiquitin-conjugating enzymes, in in vitro differentiation and cell cycle behavior of HT-29-M6 intestinal mucosecretory cells. Mol Cell Biol 1998; 18: 576-589.

18. Hofmann RM, Pickart CM. Noncanonical MMS2-encoded ubiquitin-conjugating enzyme functions in assembly of novel polyubiquitin chains for DNA repair. Cell 1999; 96: 645-653.

19. McKenna S, Spyracopoulos L, Moraes T, Pastushok L, Ptak C, Xiao W et al. Noncovalent interaction between ubiquitin and the human DNA repair protein $\mathrm{Mms} 2$ is required for Ubc13mediated polyubiquitination. J Biol Chem 2001; 276: 40120-40126.

20. Deng L, Wang C, Spencer E, Yang L, Braun A, You J et al. Activation of the IkB kinase complex by TRAF6 requires a dimeric ubiquitin-conjugating enzyme complex and a unique polyubiquitin chain. Cell 2000; 103: 351-361.

21. Andersen PL, Zhou H, Pastushok L, Moraes T, McKenna S, Ziola B et al. Distinct regulation of Ubc13 functions by the two ubiquitin-conjugating enzyme variants Mms2 and Uev1A. J Cell Biol 2005; 170: 745-755.

22. Wu Z, Shen S, Zhang Z, Zhang W, Xiao W. Ubiquitin-conjugating enzyme complex Uev1AUbc13 promotes breast cancer metastasis through nuclear factor-kB mediated matrix metalloproteinase-1 gene regulation. Breast Cancer Res 2014; 16: R75.

23. Ashcroft AJ, Davies FE, Morgan GJ. Aetiology of bone disease and the role of bisphosphonates in multiple myeloma. Lancet Oncol 2003; 4: 284-292.

24. Lamothe B, Webster WK, Gopinathan A, Besse A, Campos AD, Darnay BG. TRAF6 ubiquitin ligase is essential for RANKL signaling and osteoclast differentiation. Biochem Biophys Res Commun 2007; 359: 1044-1049.

25. Liu J, Li X, Zhang H, Gu R, Wang Z, Gao Z et al. Ubiquitin E3 ligase Itch negatively regulates osteoblast function by promoting proteasome degradation of osteogenic proteins. Bone Joint Res 2017; 6: 154-161

26. Pastushok L, Moraes TF, Ellison MJ, Xiao W. A single Mms2 "key" residue insertion into a Ubc13 pocket determines the interface specificity of a human Lys63 ubiquitin conjugation complex. J Biol Chem 2005; 280: 17891-17900.

27. Luu HH, Song WX, Luo X, Manning D, Luo J, Deng ZL et al. Distinct roles of bone morphogenetic proteins in osteogenic differentiation of mesenchymal stem cells. J Orthop Res 2007; 25: 665-677. 
28. Sandberg AA, Bridge JA. Updates on the cytogenetics and molecular genetics of bone and soft tissue tumors: osteosarcoma and related tumors. Cancer Genet Cytogenet 2003; 145: $1-30$.

29. Ginestier C, Hur MH, Charafe-Jauffret E, Monville F, Dutcher J, Brown M et al. ALDH1 is a marker of normal and malignant human mammary stem cells and a predictor of poor clinical outcome. Cell Stem Cell 2007; 1: 555-567.

30. Huang EH, Hynes MJ, Zhang T, Ginestier C, Dontu G, Appelman H et al. Aldehyde dehydrogenase 1 is a marker for normal and malignant human colonic stem cells (SC) and tracks SC overpopulation during colon tumorigenesis. Cancer Res 2009; 69: 3382-3389.

31. Cores EP, Holland JF, Wang JJ, Sinks LF. Doxorubicin in disseminated osteosarcoma. JAMA 1972; 221: 1132-1138.

32. Rosen G, Suwansirikul S, Kwon C, Tan C, Wu SJ, Beattie EJ Jr. et al. High-dose methotrexate with citrovorum factor rescue and adriamycin in childhood osteogenic sarcoma. Cancer 1974; 33: 1151-1163.

33. Feng $\mathrm{XH}$, Derynck R. Specificity and versatility in tgf-beta signaling through Smads. Annu Rev Cell Dev Biol 2005; 21: 659-693.

34. Massague J, Seoane J, Wotton D. Smad transcription factors. Genes Dev 2005; 19 : 2783-2810.

35. Shi Y, Massague J. Mechanisms of TGF-b signaling from cell membrane to the nucleus. Cell 2003; 113: 685-700.

36. Lonn P, Moren A, Raja E, Dahl M, Moustakas A. Regulating the stability of TGFb receptors and Smads. Cell Res 2009; 19: 21-35.

37. Zhu H, Kavsak P, Abdollah S, Wrana JL, Thomsen GH. A SMAD ubiquitin ligase targets the BMP pathway and affects embryonic pattern formation. Nature 1999; 400: 687-693.

38. Andrews PS, Schneider S, Yang E, Michaels M, Chen $\mathrm{H}$, Tang $\mathrm{J}$ et al. Identification of substrates of SMURF1 ubiquitin ligase activity utilizing protein microarrays. Assay Drug Dev Technol 2010; 8: 471-487.

39. Xiao W, Lin SL, Broomfield S, Chow BL, Wei YF. The products of the yeast MMS2 and two human homologs (hMMS2 and CROC-1) define a structurally and functionally conserved Ubc-like protein family. Nucleic Acids Res 1998; 26: 3908-3914.

40. Wrighton $\mathrm{KH}$, Lin X, Feng XH. Phospho-control of TGF-b superfamily signaling. Cell Res 2009; 19: 8-20.

41. Pickart CM, Fushman D. Polyubiquitin chains: polymeric protein signals. Curr Opin Chem Biol 2004; 8: 610-616.
42. Ying SX, Hussain ZJ, Zhang YE. Smurf1 facilitates myogenic differentiation and antagonizes the bone morphogenetic protein-2-induced osteoblast conversion by targeting Smad5 for degradation. J Biol Chem 2003; 278: 39029-39036.

43. Li L, Xin H, Xu X, Huang M, Zhang X, Chen Y et al. CHIP mediates degradation of Smad proteins and potentially regulates Smad-induced transcription. Mol Cell Biol 2004; 24: 856-864.

44. Zhao M, Qiao M, Harris SE, Oyajobi BO, Mundy GR, Chen D. Smurf1 inhibits osteoblast differentiation and bone formation in vitro and in vivo. J Biol Chem 2004; 279: 12854-12859.

45. Ma L, Broomfield S, Lavery C, Lin SL, Xiao W, Bacchetti S. Up-regulation of CIR1/CROC1 expression upon cell immortalization and in tumor-derived human cell lines. Oncogene 1998; 17: $1321-1326$.

46. Wang C, Deng L, Hong M, Akkaraju GR, Inoue J, Chen ZJ. TAK1 is a ubiquitin-dependent kinase of MKK and IKK. Nature 2001; 412: 346-351.

47. Zhou H, Wertz I, O'Rourke K, Ultsch M, Seshagiri S, Eby M et al. Bcl10 activates the NF-kB pathway through ubiquitination of NEMO. Nature 2004; 427: 167-171.

48. Yang WL, Wang J, Chan CH, Lee SW, Campos AD, Lamothe B et al. The E3 ligase TRAF6 regulates Akt ubiquitination and activation. Science 2009; 325: 1134-1138.

(i) Cell Death and Disease is an open-access journal published by Nature Publishing Group. This work is licensed under a Creative Commons Attribution 4.0 International License. The images or other third party material in this article are included in the article's Creative Commons license, unless indicated otherwise in the credit line; if the material is not included under the Creative Commons license, users will need to obtain permission from the license holder to reproduce the material. To view a copy of this license, visit http://creativecommons.org/licenses/by/4.0/

(C) The Author(s) 2017

Supplementary Information accompanies this paper on Cell Death and Disease website (http://www.nature.com/cddis) 